\title{
How can nanobiotechnology oversight advance science and industry \\ Examples from environmental, health, and safety studies of nanoparticles (nano-EHS)
}

\author{
Journal Article \\ Author(s): \\ Wang, Jing; Asbach, Christof; Fissan, Heinz; Huelser, Tim; Kuhlbusch, Thomas A.J.; Thompson, Drew; Pui, David Y.H. \\ Publication date: \\ 2011-04 \\ Permanent link: \\ https://doi.org/10.3929/ethz-b-000035416
}

Rights / license:

In Copyright - Non-Commercial Use Permitted

Originally published in:

Journal of Nanoparticle Research 13(4), https://doi.org/10.1007/s11051-011-0236-z 


\title{
How can nanobiotechnology oversight advance science and industry: examples from environmental, health, and safety studies of nanoparticles (nano-EHS)
}

\author{
Jing Wang • Christof Asbach • Heinz Fissan • \\ Tim Hülser • Thomas A. J. Kuhlbusch • \\ Drew Thompson • David Y. H. Pui
}

Received: 7 January 2011 / Accepted: 13 January 2011 / Published online: 28 January 2011

(C) Springer Science+Business Media B.V. 2011

\begin{abstract}
Nanotechnology has great potential to transform science and industry in the fields of energy, material, environment, and medicine. At the same time, more concerns are being raised about the occupational health and safety of nanomaterials in the workplace and the implications of nanotechnology on the environment and living systems. Studies on environmental, health, and safety (EHS) issues of nanomaterials have a strong influence on public acceptance of nanotechnology and, eventually, affect its sustainability. Oversight and regulation by government agencies and non-governmental organizations (NGOs) play significant roles in ensuring responsible and environmentally friendly development of nanotechnology. The EHS studies of nanomaterials can provide data and information to help the development of regulations and guidelines. We
\end{abstract}

\footnotetext{
J. Wang $(\bowtie)$

Institute of Environmental Engineering, ETH Zurich,

Zurich 8093, Switzerland

e-mail: jing.wang@ifu.baug.ethz.ch

J. Wang

Empa, 8600 Dübendorf, Switzerland

C. Asbach · H. Fissan · T. Hülser · T. A. J. Kuhlbusch Institut für Energie-und Umwelttechnik eV (IUTA), 47229 Duisburg, Germany

D. Thompson · D. Y. H. Pui

Particle Technology Laboratory, University of Minnesota, Minneapolis, MN 55414, USA
}

present research results on three aspects of EHS studies: physico-chemical characterization and measurement of nanomaterials; emission, exposure, and toxicity of nanomaterials; and control and abatement of nanomaterial releases using filtration technology. Measurement of nanoparticle agglomerates using a newly developed instrument, the Universal NanoParticle Analyzer (UNPA), is discussed. Exposure measurement results for silicon nanoparticles in a pilot scale production plant are presented, as well as exposure measurement and toxicity study of carbon nanotubes (CNTs). Filtration studies of nanoparticle agglomerates are also presented as an example of emission control methods.

Keywords Characterization - Control - Emission · Exposure · Filtration · Nano-EHS · Oversight . Regulation · Toxicity · Governance

\section{Introduction}

The quantity of engineered nanomaterials is expected to grow significantly in the next several years (Roco 2006). Analysts have estimated that the worldwide market for nanomaterials will be 700-1000 billion Euro in 2011 (Nanosafe.org). Examples in the semiconductor industry include silica and alumina nanoparticles in chemical-mechanical polishing 
processes, potential use of hafnium oxide nanoparticles in advanced immersion lithography, and carbon nanotubes (CNTs) that may be used in self-assembly or advanced packaging processes. Nanoparticles may enter human body through various pathways. Airborne exposure with inhalable uptake is currently viewed as the most critical exposure route. The combination of the specific material properties and the extremely high specific surface area of nanoparticles may pose a threat to workers' health. Nanomaterials can also potentially lead to new hazards or increased risks to the environment (McMurry et al. 2004; Oberdörster et al. 2005; Maynard 2006; Maynard and Pui 2007).

Sustainability issues and environmental, health, and safety (EHS) aspects of nanomaterials are becoming a focus of government agencies. The U.S. National Institute for Occupational Safety and Health (NIOSH) has designated EHS impacts of nanomaterials as one of the focuses of the strategic plan. NIOSH plans to develop recommended exposure limits (RELs) for ultrafine titanium dioxide and CNTs for the period of 2009-2012 (NIOSH 2009). The U.S. National Science Foundation (NSF) has established two Engineering Research Centers for Environmental Implications of Nanotechnology (CEIN). The European Union and its member states have established research consortia NANOSAFE1 and 2, MARINA, NANOCARE, and NANOGEM, among others. Industry has also raised awareness of EHS issues. Intel formed a Nanotechnology EHS Management Review Committee and set policy to manage and handle nanomaterials in a safe and environmentally responsible manner. Many personal protective equipment (respirators, garment, filter cartridges) manufacturers are testing their products for nanomaterials. Instrument companies, research institutions, and government agencies are active in developing personal samplers for nanomaterials to determine exposure levels in work places.

EHS studies of nanomaterials can provide valuable input for oversight and regulation. For example, NIOSH needs data on exposure levels and toxicity to develop RELs for CNTs. Around the core of EHS studies, we will present research results on three aspects: physico-chemical characterization and measurement of nanomaterials; emission, exposure, and toxicity of nanomaterials; and emission control and abatement of nanomaterial release using filtration technology (Fig. 1). Information on the nanomaterials, including the concentration, size, morphology, chemical composition, and crystallinity, plays an important role in determining their EHS impacts. We have done extensive studies of instrument development to characterize and measure nanoparticles. A recently developed instrument, the universal nanoparticle analyzer (UNPA), will be discussed, and its application in agglomerate measurement will be reviewed. The EHS impacts of nanomaterials occur when these materials are released into the environment or taken up by human beings. Thus, the emission and exposure levels of nanoparticles are critical for evaluation of risk. We will present exposure measurement results for silicon nanoparticles in a pilot scale plant and for CNTs during the production of nanocomposites in an industrial facility. Toxicity for many novel nanomaterials, including silicon nanoparticles and CNTs, is not well understood. Here we review our study on toxicity of CNTs delivered through an airborne route. To control nanomaterial release and reduce the emission and exposure, filtration technology is often used. Results on nanoparticle agglomerate filtration and loading will be discussed.

\section{Universal nanoparticle analyzer}

Need for nanoparticle agglomerate measurement

Nanoparticle agglomerates are pervasive in atmospheric sciences, air pollution, and material manufacturing.

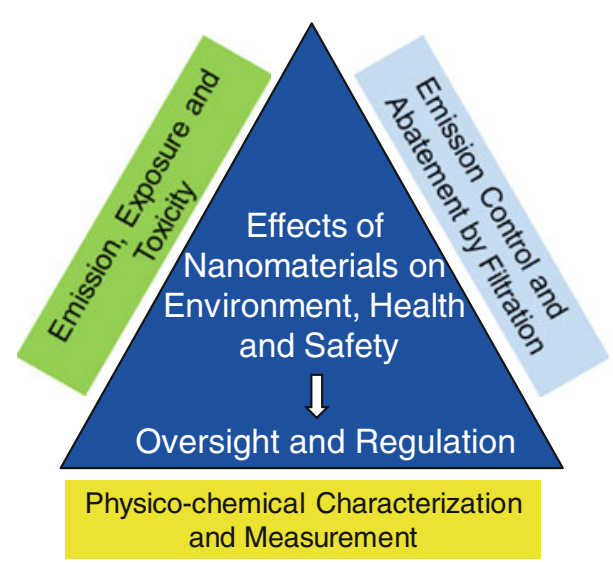

Fig. 1 Key research aspects for EHS studies of nanomaterials 
Combustion processes are used to manufacture a variety of materials in agglomerate form, including fumed silica, titanium dioxide, and carbon black. Measurement of agglomerates is of great importance to many applications (Pratsinis 1998). Agglomerates may possess complicated structures, which makes measurement a difficult task. One of the most common methods for agglomerate measurement is electron microscopy, which can provide direct measurement of the structural properties (Cai et al. 1993; Koylu et al. 1995; Neimark et al. 1996; Park et al. 2004a; Rogak et al. 1993; Samson et al. 1987; Wentzel et al., 2003; Shin et al. 2009a). However, taking electrical micrographs and performing image analysis can be time consuming and expensive, especially since particles need to be sampled on substrates before they can be analyzed. In addition, interpretation of the 2D images for $3 \mathrm{D}$ results may rely on assumptions and cause inaccuracy.

Researchers have developed combined measurements from different instruments to obtain morphology information of agglomerates. Van Gulijk et al. (2004) and Maricq and Xu (2004) combined the differential mobility analyzer (DMA) and electrical low pressure impactor (ELPI) to measure soot particles. DeCarlo et al. (2004) and Slowik et al. (2004) combined measurement of the mobility diameter and vacuum aerodynamic diameter to characterize particle morphology and density. Combination of the mobility measurement by DMA and particle mass measurement by aerosol particle mass analyzer (APM) have been applied by Park et al. (2004a, b) to diesel exhaust particles and by Geller et al. (2006) to urban aerosols. This method can give the particle effective density and fractal dimension. Olfert et al. (2007) used DMA and a Couette centrifugal particle mass analyzer (Couette CPMA) to measure the effective density and fractal dimension of diesel particles. Shin et al. (2009b) and Kim et al. (2009a) used the DMA-APM combination to measure silver agglomerates. Park et al. (2008) reviewed several tandem measurements in which submicrometer particles classified according to the electrical mobility were then characterized with an additional method. Measurements reviewed included mobility plus mass, aerodynamic diameter, integrated or multiangle light scattering, and composition by single particle mass spectrometry and electron microscopy.
Fast and online measurement for agglomerates is required in many scenarios, including measuring fast changing agglomerates, quality control for material manufacturing, and monitoring potentially toxic airborne agglomerates. Most of the current aerosol instruments are designed for spherical particles. Therefore, there is a need for instruments capable of fast and online measurement of gas-borne nanoparticle agglomerates.

\section{Theoretical background for UNPA}

We have developed the instrument UNPA for online measurement of gas-borne nanoparticle agglomerates (Wang et al. 2010; Shin et al. 2010). UNPA utilizes DMA, condensation particle counter (CPC), and nanoparticle surface area monitor (NSAM) to characterize airborne nanoparticle morphology and measure the number, surface area, and volume distributions of airborne nanoparticles. The key parameter measured is the UNPA sensitivity, which is defined as the current (fA) measured by the NSAM divided by the number concentration measured by the CPC $\left(\# / \mathrm{cm}^{3}\right)$

$S=I / N\left(\mathrm{fA} \mathrm{cm}^{3}\right)$.

Charging theories of Chang (1981) for aerosol particles of arbitrary shape indicate that the geometric surface area and electrical capacitance of the particles are two important parameters to determine the mean charge of non-spherical particles. The electrical capacitance of agglomerates may be computed using a variational method proposed by Brown and Hemingway (1995). The surface area of loose agglomerates may be calculated using a mobility analysis developed by Lall and Friedlander (2006). Shin et al. (2010) combined the above analyses to show that the electrical capacitance of loose agglomerates is larger than that of spherical particles with the same mobility, and loose agglomerates can gain more charges from unipolar charging. The calculated mean charge on agglomerates as a function of the mobility diameter $d_{\mathrm{m}}$ is shown in Fig. 2. The results show that the mean charges of agglomerates are larger compared to those of spheres of the same $d_{\mathrm{m}}$. The calculation using Chang's (1981) theory in the continuum regime for branched chain agglomerates with an aspect ratio of 1.6 agreed reasonably well with the experimental data for silver agglomerates. 


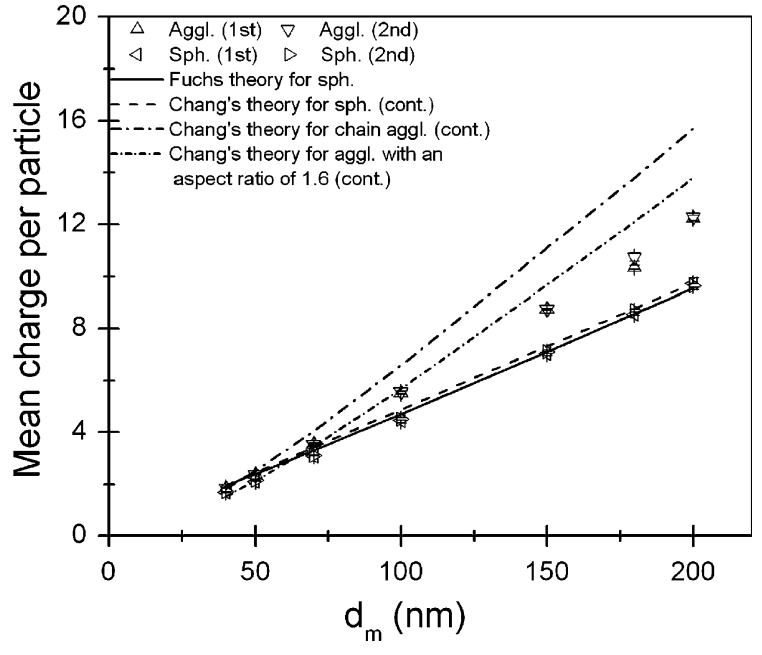

Fig. 2 Comparison of the mean charge per particle for openstructured agglomerates and spheres (Shin et al. 2010). The curves are from theoretical models and the symbols represent experimental data

The primary particle size plays an important role in determination of the surface area and electrical capacitance, thus the charges on agglomerates. The UNPA sensitivity is related to the primary particle size. We found that the UNPA sensitivity can be correlated to the primary particle size through a power law relation (Wang et al. 2010)

$S=c_{2}\left(\frac{12 \pi \lambda}{c^{*} d_{\mathrm{p}}^{2}} \frac{d_{\mathrm{m}}}{C_{\mathrm{c}}}\right)^{k} c_{1}\left(d_{\mathrm{p}}\right)^{h}=A\left(\frac{d_{\mathrm{m}}}{C_{\mathrm{c}}}\right)^{k}\left(d_{\mathrm{p}}\right)^{h-2 k}$

where $c^{*}$ is a constant regarding particle orientation and $C_{\mathrm{c}}\left(d_{\mathrm{m}}\right)$ is the Cunningham slip correction factor, $c_{1}, c_{2}, k$, and $h$ are constants which can be determined from the experimental data. Then the sensitivity data from the experiments can be fitted into (2) to determine the primary particle diameter $d_{\mathrm{p}}$. Once the primary particle size is determined, surface area and volume of the agglomerates can be calculated.

\section{UNPA measurement results}

We used the UNPA to measure silver spheres and agglomerates of silver, $\mathrm{SiO}_{2}$, and $\mathrm{TiO}_{2} . \mathrm{SiO}_{2}$ and $\mathrm{TiO}_{2}$ agglomerates were generated by a diffusion burner. The sensitivities for silver spheres and loose agglomerates are the lowest and highest, respectively,

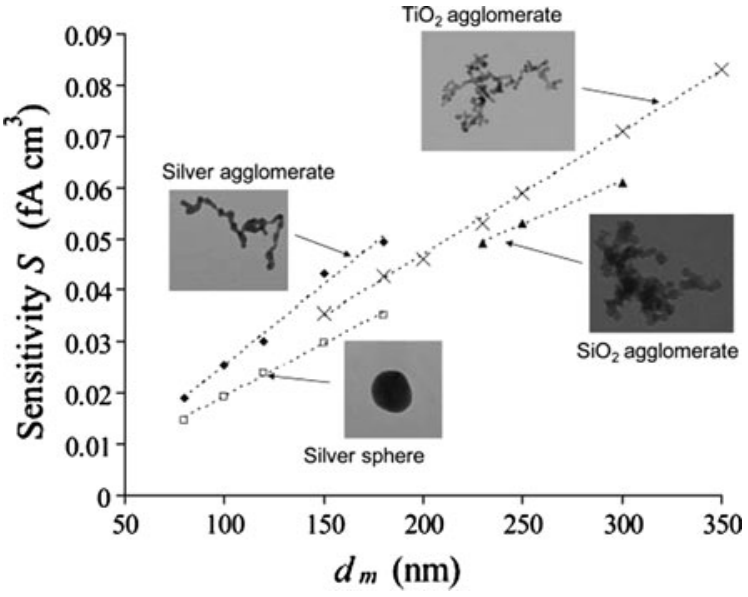

Fig. 3 Measured UNPA sensitivity for silver agglomerates and spheres, $\mathrm{SiO}_{2}$, and $\mathrm{TiO}_{2}$ agglomerates

among our sensitivity data (Fig. 3). The sensitivities for $\mathrm{TiO}_{2}$ and $\mathrm{SiO}_{2}$ agglomerates are between the upper and lower bounds.

We also used UNPA to measure gold and nickel nanoparticle agglomerates from a spark discharge generator. We determined the primary particle sizes for agglomerates using the sensitivity data and Eq. 2 . We also analyzed electron micrographs and obtained the primary particle sizes. A comparison of the primary particle sizes from the two methods is shown in Table 1. It can be seen that the agreement for the primary particle size is good, and UNPA can measure primary particles in a rather broad size range.

For loose agglomerates, UNPA can measure the number, surface area, and volume distributions. We show the results for silver agglomerates in Fig. 4. The distributions based on spheres are also plotted for comparison. The difference in the volume distributions is substantial. The results show that the UNPA measurement can potentially improve the measure of distribution based on spheres significantly.

\section{Exposure measurement for silicon nanoparticle production}

Workplace exposure measurement

Data on fate and transport of engineered nanomaterials released from manufacturing facilities are still 
Table 1 A comparison for the primary particle sizes obtained from the UNPA sensitivity analysis and electron microscopy (EM)

\begin{tabular}{llll}
\hline & $\begin{array}{l}d_{\mathrm{p}} \text { from UNPA } \\
\text { sensitivity }(\mathrm{nm})\end{array}$ & $\begin{array}{l}d_{\mathrm{p}} \text { from } \\
\mathrm{EM}(\mathrm{nm})\end{array}$ & $\begin{array}{l}\text { Standard deviation } \\
\text { of } d_{\mathrm{p}} \text { from EM (nm) }\end{array}$ \\
\hline $\mathrm{TiO}_{2}$ agglomerates & 22.8 & 19.9 & 7.5 \\
$\mathrm{SiO}_{2}$ agglomerates & 32.5 & 27.3 & 9.3 \\
$\mathrm{Au}$ agglomerates & 5.97 & 7.90 & 1.47 \\
$\mathrm{Ni}$ agglomerates & 4.09 & 6.56 & 0.98 \\
\hline
\end{tabular}

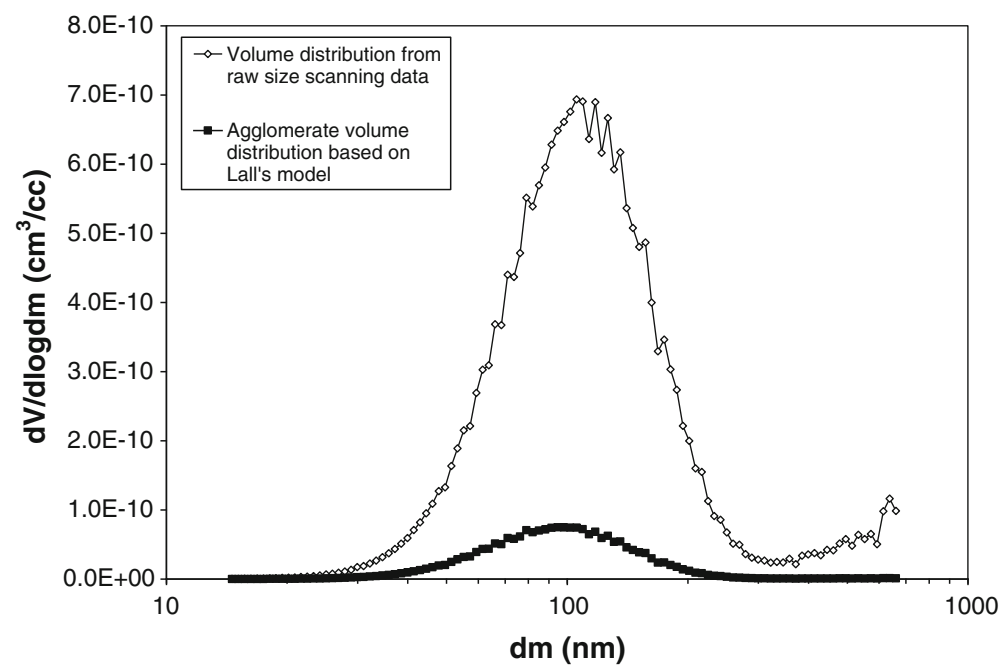

Fig. 4 The raw size scanning result assuming spheres overestimates the agglomerate volume concentration by about ten times compared to the result assuming loose agglomerates limited. The few reports on workplace exposures suggest that engineered nanomaterials are released at high mass and/or number concentrations only under unusual circumstances (Han et al. 2008; Kuhlbusch et al. 2004; Kuhlbusch and Fissan 2006; Maynard et al. 2004). However, there still exists the need to study exposure levels to other engineered nanomaterial types in occupational and environmental settings.

Production cycle of silicon nanoparticles in the pilot scale plant

We performed exposure measurement at a pilot scale nanoparticle production plant at the Institut für Energie-und Umwelttechnik eV, IUTA, Duisburg, Germany. The facility is designed to produce nanoparticles in the $\mathrm{kg}$ /day range. Our measurement covered the whole production cycle of silicon nanoparticles, including generation from the reactor, collection by filters, bagging, packaging, and cleaning of the system. Silicon nanoparticles were produced in a hot-wall reactor, in which the precursor gas was thermally decomposed to form the nanoparticles. The primary particle size was about 30-60 nm, and the agglomerates formed by them were about several hundred nanometers. The generated particles were covered by a naturally grown oxide layer on the surface, but the core part was pure silicon (Hülser et al. 2010). The reactor was connected through tubing to the filter housing, where the particles were collected on filters. In the bagging process, reverse pulsing was applied to blow the particles off the filter into a plastic bag underneath. The bagging process is completely sealed so that a release of particles can only be expected in the event of an accident. The plastic bag was then sealed and removed from the system, ready for shipping. In a separate packaging process, a worker took out particles from the bag using a spoon and filled laboratory glass tubes with the particles for quality analysis. The cleaning process involved purging the tubing system with pressurized air, opening the tubing system, and manual cleaning. 
Exposure measurement results

A suite of aerosol instruments were used for the measurement, including the fast mobility particle sizer (FMPS, TSI model 3091, particle size range $5.6-560 \mathrm{~nm}, 1 \mathrm{~s}$ time resolution), nanoparticle surface area monitor (NSAM, TSI model 3550, particle size range $<1 \mu \mathrm{m}, 1 \mathrm{~s}$ time resolution), handheld condensation particle counter (CPC, TSI model 3007, particle size range $>10 \mathrm{~nm}, 1 \mathrm{~s}$ time resolution), and scanning mobility particle sizer (SMPS, TSI model 3936 with long DMA, $0.3 \mathrm{~L} / \mathrm{min}$ aerosol flow rate, $3 \mathrm{~L} / \mathrm{min}$ sheath flow rate, size range $15-750 \mathrm{~nm}$, 5 min time resolution). A second set of the instruments were deployed outside of the enclosure of the production facility to monitor the particle level at the background. This approach helped us to distinguish particles released by the production processes from those generated by other background sources.

Our results showed that the particle concentration in the production facility was mostly comparable with that in the background for the processes we measured. Figure 5 shows the total particle number concentration (derived from FMPS measurements) and the NSAM reading for lung-deposited surface area concentration during the production process when the reactor was running. Both the measurements in the plant and at the background are shown. The two sets of the instruments had certain offsets that caused discrepancies between the curves. We can still see that the concentrations in the plant and in the background had the same trend. Some concentration fluctuations occurred in the background, probably due to activities of workers outside of the production plant. There was no evidence of particle concentration increase in the pilot plant due to nanoparticle production. This is mainly due to the closed system of production, which very effectively contained the nanoparticles produced.

High particle concentrations were observed only in special cases. For example, particle concentration spiked when the tubing was open and impacted upon during manual cleaning (Fig. 6). We observed that there was particle deposition on the tube walls. Particles were dislodged from the wall during cleaning and detected by our instruments. These particles were mostly in agglomerated form and in the size range of $200-300 \mathrm{~nm}$.

Our results show that nanoparticle release from a manufacturing process can be minimized with proper procedures, and that the closed system of production is very effective in containing produced nanoparticles, assuring safe production. However, protection for workers is still needed during special processes, such as cleaning and packaging. Furthermore, there is a strong need to study the potential release of and exposure to nanomaterials during further (industrial) processing, use by consumers, and recycling. Only a
Fig. 5 The total particle number concentration and the NSAM reading for lungdeposited surface area concentration during the production process. Both the measurements in the plant and at the background are shown

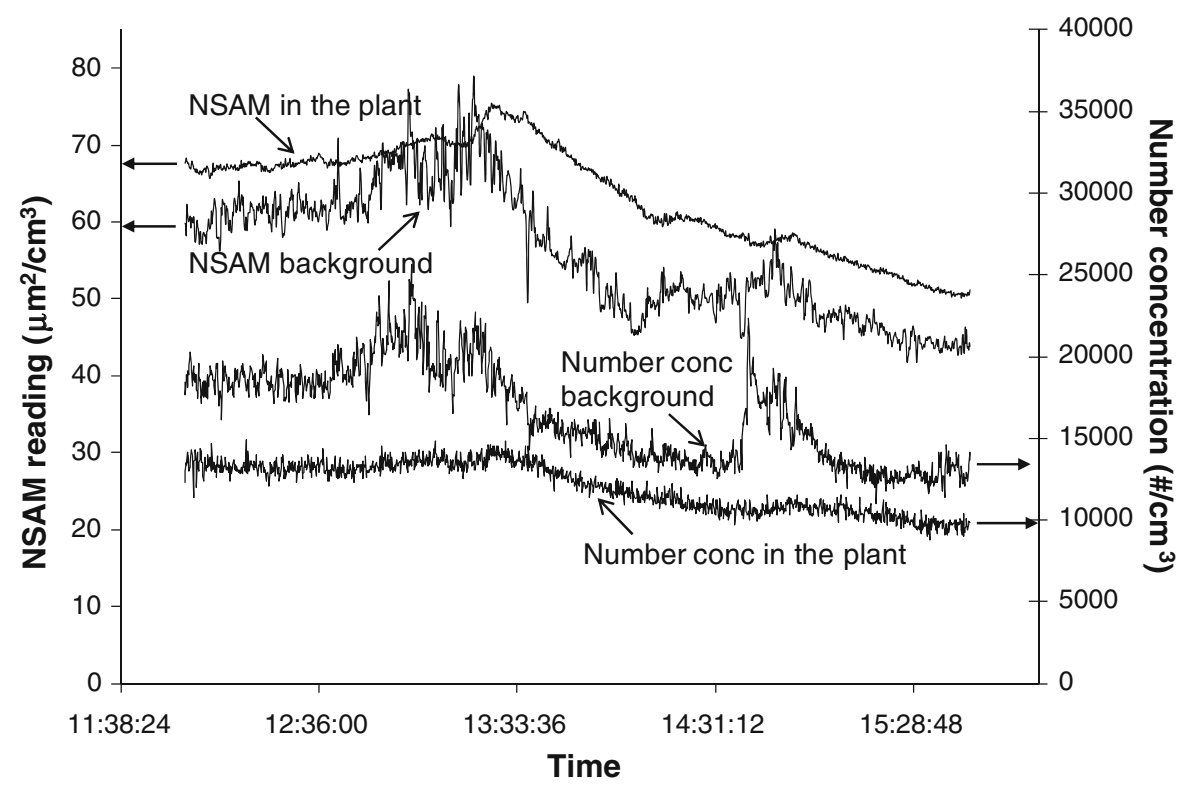


Fig. 6 The total particle number concentration and the NSAM reading for lungdeposited surface area concentration during the manual cleaning process

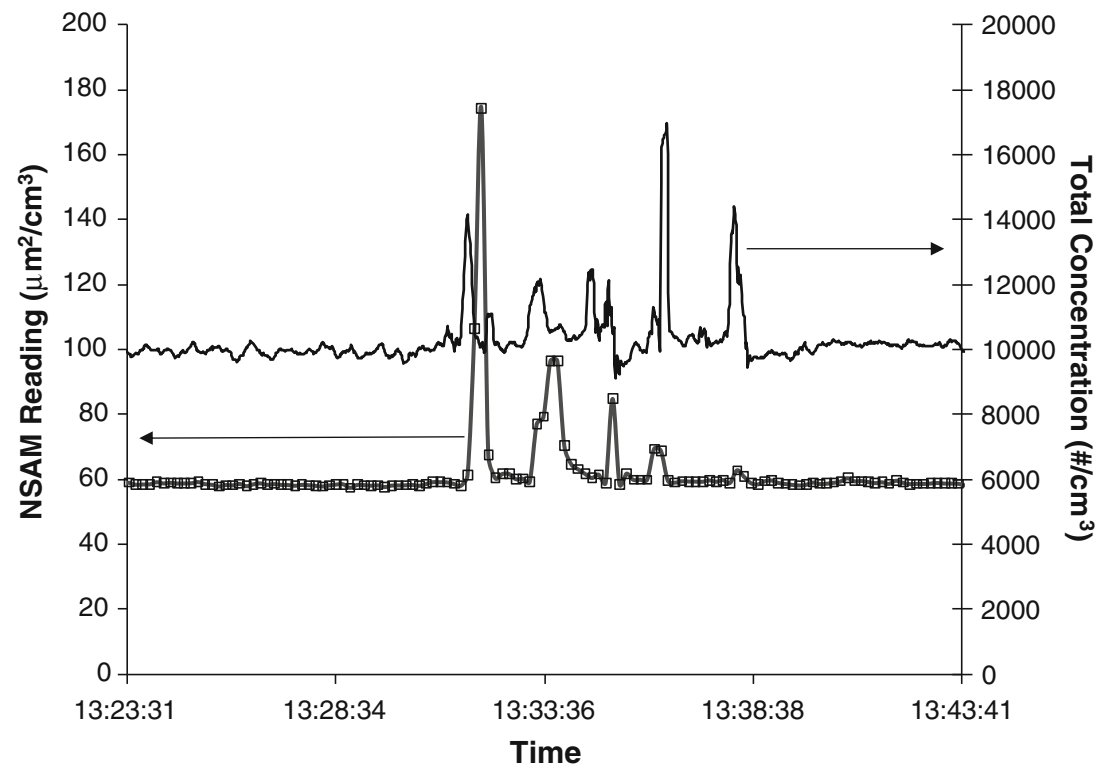

holistic approach assessing potential exposure and hazard during the entire lifecycle will lead to general acceptance of "nano-products" and, hence, guarantee sustainable development of the nanotechnology industry.

\section{Exposure measurement and toxicity study for CNTs}

\section{Background for CNT exposure and toxicity studies}

The unique properties of CNTs have led to their increased use in advanced materials. CNTs are used in structural composites for sporting equipment, conductive plastics, electron field emitters, semiconductor devices, and many other applications. As more industries incorporate CNTs into consumer products, the opportunities for worker exposure will rise. Multi-wall CNTs may have dimensions similar to asbestos fibers. Such similarity has raised concerns that CNTs may cause negative health effects similar to asbestos fibers. Poland et al. (2008) reported that CNTs introduced into the abdominal cavity of mice showed asbestos-like pathogenicity in a pilot study. Takagi et al. (2008) and Sakamoto et al. (2009) reported that multi-wall CNTs caused mesothelioma in mice and rats. Ryman-Rasmussen et al. (2009a, b) studied the effect of inhaled CNTs in the airway system. NIOSH specified identification of the longterm health effects of CNTs in its strategic plan for 2009-2012 (NIOSH 2009). We review our exposure measurement of CNTs in the production of nanocomposites and toxicity studies using airborne CNTs.

Exposure measurement for production of CNTimbedded nanocomposites

We measured exposure in an industrial production facility for CNT-embedded nanocomposites. In the extrusion operation, CNTs were mixed with melted polymer and other compounds to produce nanocomposite pellets. First, polymer was melted and mixed with CNTs. The mixture was extruded from a die into a water bath. Cooled strands passed through a dryer before entering a cutter. The pieces were fed into a second extruder with a CNT dispersing agent. At the exit of the second extruder, the strands were pelletized. The pellets passed through a shaker and a cyclone for size selection.

A suite of instruments was used to obtain air-borne particle number concentration, surface area concentration, and size distribution data. The instruments were placed in the closed room near the extrusion system. The measurement results are shown in Fig. 7. The measurement duration can be divided into five periods. Period I (from 12:50 to 13:40) accounted for 

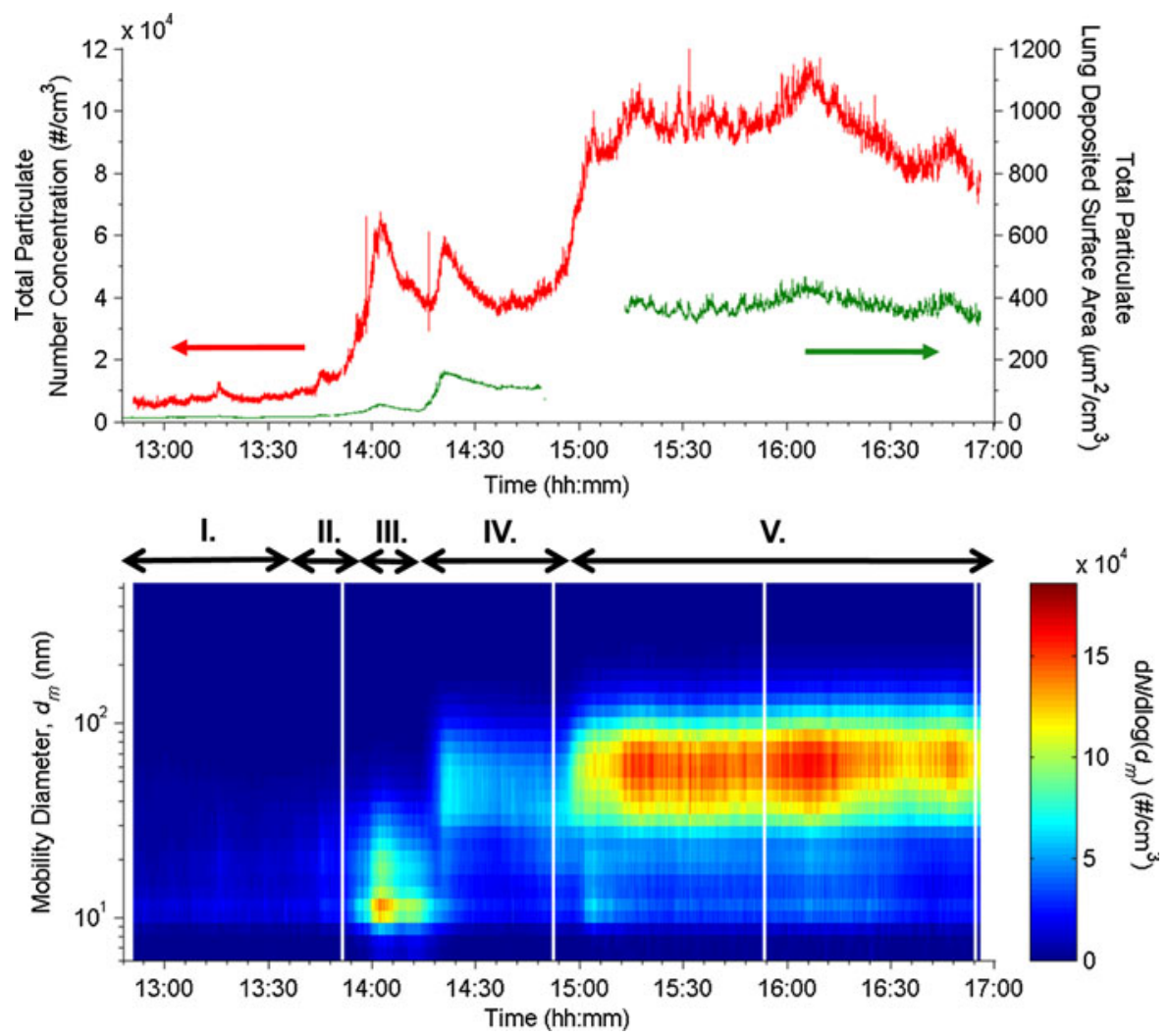

Fig. 7 Measurement for air-borne particles during the extrusion operation for CNT-imbedded nanocomposites. Upper panel shows the total number concentration and lung-deposited surface area concentration; lower panel shows the evolution of the particle number-size distribution

corroborated by the observation that the particle concentrations were highest near the extrusion barrel, and vapor was visible at the extrusion barrels. Further research is needed to determine the fraction of CNTs in the total particle concentration.

We also used a filter to collect samples for electron microscopic analysis. Examples of the SEM pictures are shown in Fig. 8. We found a number of CNT agglomerates on the filter. The sizes of the CNT agglomerates were in the range of $1-20 \mu \mathrm{m}$. The individual CNTs were much smaller, with the diameter of about $40 \mathrm{~nm}$. The CNTs were already in the agglomerated form when provided by the manufacturer. Such large agglomerates have limited mobility and are easier and safer to handle and transport. The question remains whether the CNT agglomerates can be disintegrated during the extrusion process and whether single CNTs can be released. Thus far, we have not found single CNTs on the filter samples. 


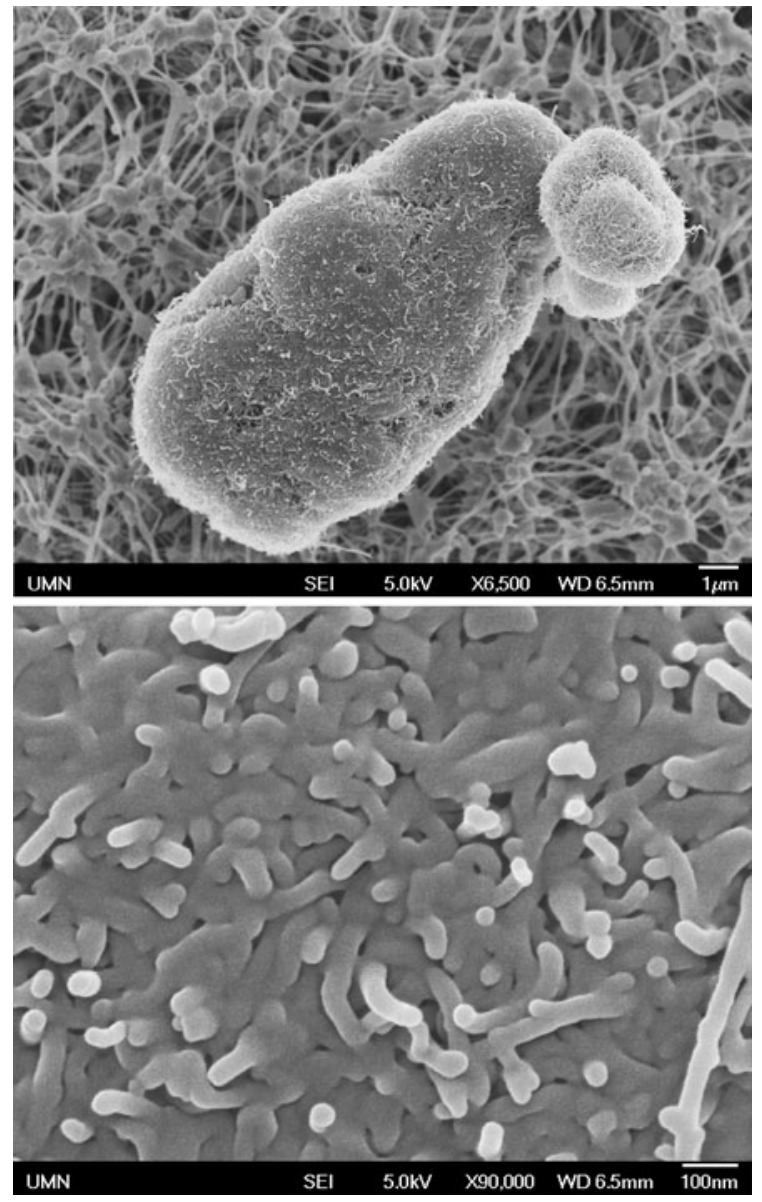

Fig. 8 Examples of SEM images of the CNTs agglomerates collected on filters during the extrusion process. The picture on the right is a magnified local view of the one on the left

Further research will be performed to identify possibly released single CNTs.

Animal inhalation exposure test using airborne CNTs

We developed an electrospray system to disperse and aerosolize CNT colloidal suspensions with controlled degree of agglomeration (Kim et al. 2010). A syringe pump is used to inject the CNT suspensions into a capillary tube. The liquid exiting through the capillary tube is exposed to a strong electric field. The non-uniform electric field causes the liquid meniscus to assume a conical shape established by the balance between the surface tension force and electrical force on the cone. Very small liquid droplets containing CNTs come out of the tip of the capillary. The droplet

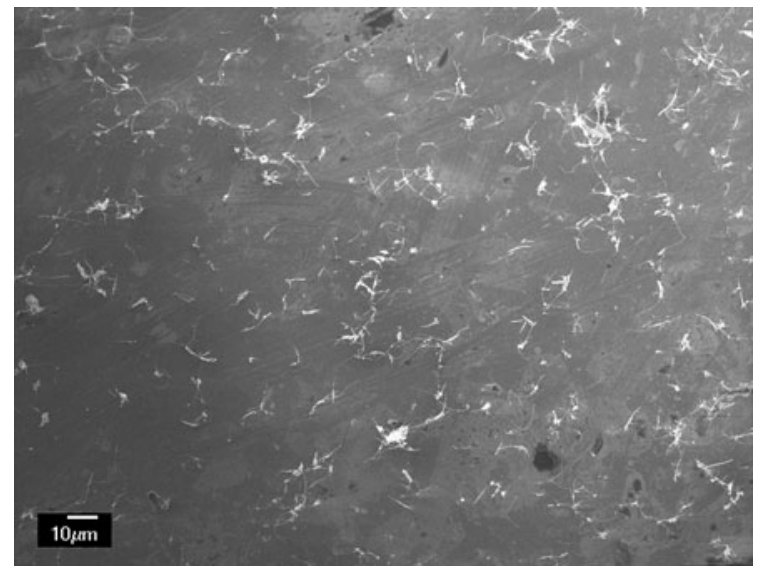

Fig. 9 SEM image of electrosprayed multi-wall CNTs for animal inhalation test

size produced by this mechanism can be monodisperse and controllable by varying the electrical properties of the liquid and the liquid feed rate. The liquid evaporates quickly, and airborne CNTs are obtained. To achieve high throughput, a large capillary (ID $2.0 \mathrm{~mm}$ ), high suspension flow rate (up to $9 \mathrm{~mL} / \mathrm{h}$ ), and a focusing shield with sheath air can be used. The focusing shield narrows the spray angle and reduces particle loss on the chamber wall. The SEM image (Fig. 9) of the electrosprayed multi-wall CNTs (MWCNT-7, Mitsui Co., Japan) shows that the CNTs are well-dispersed, with limited agglomerated packets. The large agglomerates of the order of tens of microns that are often seen in CNT powders or suspensions are avoided. This technique provides opportunities for toxicity testing of individual CNTs.

Animal inhalation tests were performed in a system shown in Fig. 10. The system consisted of the electrospray generator, an alcohol scrubber to remove the ethanol used for CNT dispersion, an animal inhalation chamber, and an airborne CNT sampling and measurement system. We generated airborne multi-wall CNTs (MWCNT-7, Mitsui Co., Japan) with a suspension flow rate of $3 \mathrm{~mL} / \mathrm{h}$, and the rats were exposed to the CNTs in the inhalation chamber for $4 \mathrm{~h}$ at a concentration of $800 \mu \mathrm{g} / \mathrm{m}^{3}$. At $20 \mathrm{~h}$ post-exposure, animals were killed by an overdose of i.p. pentobarbital, and the lungs were excised and lavaged five times with saline. After centrifugation $(400 \times g, 10 \mathrm{~min})$ the lavaged cells were examined by light and scanning electron microscopy. Figure 11 shows that alveolar 


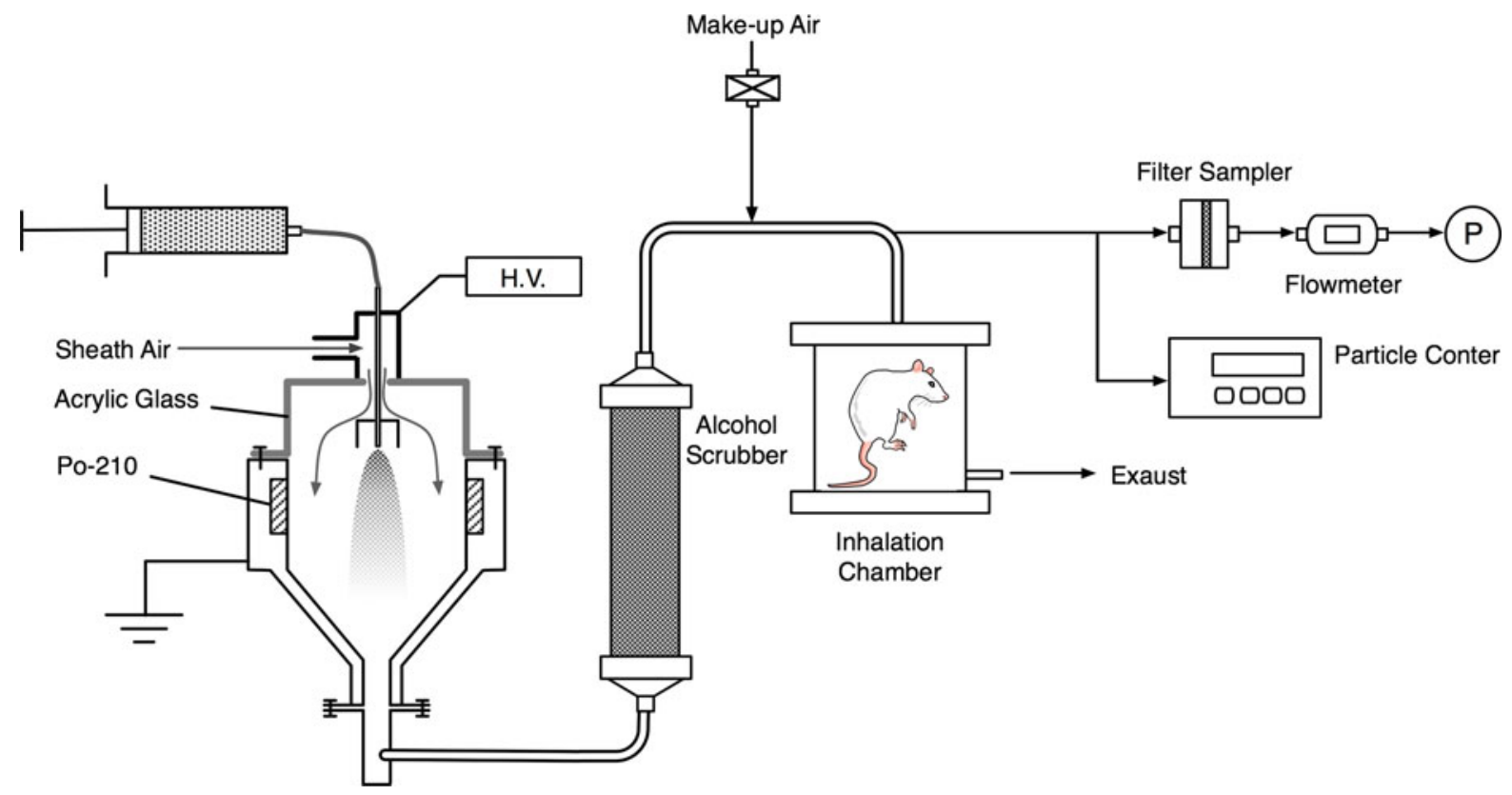

Fig. 10 Schematic of the animal inhalation exposure test system

macrophages contained the electrosprayed multi-wall CNTs; the shorter ones agglomerated inside macrophages, and the longer ones were only partly phagocytized, which might cause irritation to the lung.

\section{Filtration of nanoparticle agglomerates}

Experimental setup for silver nanoparticle agglomerate

Filtration is one of the primary technologies for nanoparticle control. Compared to spherical particles, studies of filtration of nanoparticle agglomerates are still scarce. Studies by Fu et al. (1990), Lange et al. (1999), and Kim et al. (2009a) showed that the particle morphology has substantial effects on filtration.

Figure 12 shows the schematic diagram of the test system. It consists of an agglomerate generation system, a size classification system, and a penetration measurement system. An electric tube furnace is used to generate silver nanoparticles from a pure silver powder source, which is vaporized and condensed into silver nanoparticles. Electron micrographs show that the average primary sphere size is $16.2 \mathrm{~nm}$, with a standard deviation of $3.1 \mathrm{~nm}$. These primary particles stick upon collision to form nanoparticle agglomerates in an agglomeration chamber located just downstream of the first furnace. Agglomerate sintering is carried out in the second furnace, with various temperatures ranging from room temperature to $600{ }^{\circ} \mathrm{C}$, giving rise to loose agglomerates, partially sintered agglomerates, or fully sintered spheres. The nanoparticle agglomerates are then classified by a DMA to generate monodisperse agglomerates with the same electrical mobility diameter. The agglomerates then are directed at the test filter, and the concentrations upstream and downstream of the filter are measured by two CPCs (condensation particle counter, TSI Model 3760). The fractional penetration through the filter can then be computed.

Experimental results with silver nanoparticles

The penetration results through a test filter (HE 1021, Hollingsworth and Vose) are shown in Fig. 13. Filter HE1021 is a fiberglass filter with effective fiber diameter of $2.9 \mu \mathrm{m}$, and the solid fraction and thickness are 0.05 and $0.69 \mathrm{~mm}$, respectively (Wang et al. 2007). When the mobility diameter of the particles is small (e.g., $50 \mathrm{~nm}$ ), the penetration of loose agglomerates without sintering is similar to that 


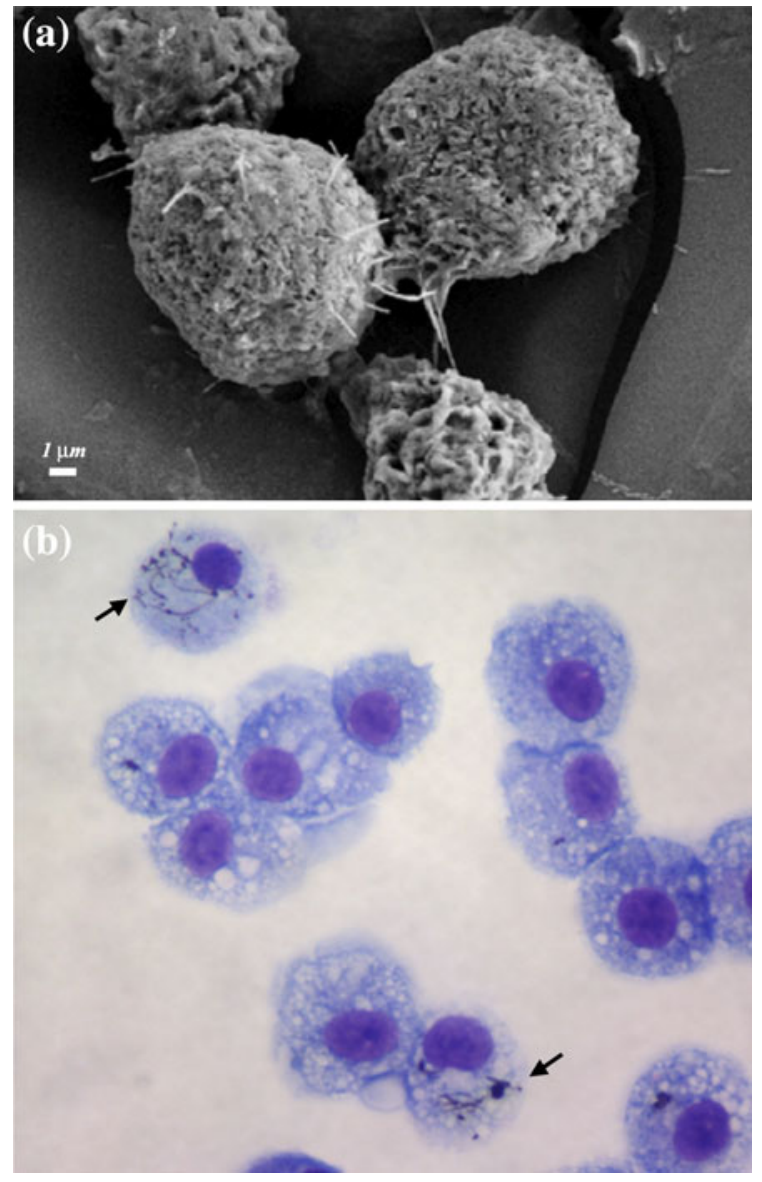

Fig. 11 a Scanning electron microscopic image and b light microscopic image of rat alveolar macrophages in lung lavage fluid $20 \mathrm{~h}$ after inhalation exposure to electrosprayed multiwall CNTs

of sintered particles. For the agglomerates with such small sizes, the number of primary spheres in one agglomerate is limited, and the morphology is close to the sintered particles. In addition, diffusion is the dominant filtration mechanism for such small particles. The diffusion coefficients of loose agglomerates and sintered particles are close when they have the same mobility diameter (Kim et al. 2009a). Thus, the values of penetration are also similar. When the mobility diameter of the particles is large (e.g., $200 \mathrm{~nm}$ ), the penetration of loose agglomerates is considerably lower than that of sintered particles. The interception mechanism plays an important role for the large particles. The loose agglomerates without sintering have branches and are more likely to be intercepted by the filter fibers, which leads to lower penetration as compared to sintered compact particles.

Filter loading test using soot agglomerates

Loading studies are very important for practical filtration systems used for emission control. For example, the diesel particulate filter (DPF) systems are increasingly popular on diesel engines, in order to meet upcoming emission legislation standards in the European Union and United States (Johnson 2006). The DPFs are designed to have relatively low initial filtration efficiencies (65-85\%), and the efficiency can increase to about $100 \%$ when loaded with diesel agglomerates. As the pressure drop caused by the loaded agglomerates increases, a regeneration process is needed to burn off the accumulated particulates. Thus, the loading characteristics play a significant role for DPF operation and regeneration strategy.

We performed loading tests in the dust cake regime using soot particles from a diffusion burner (Kim et al. 2009b). The mode of the number distribution of the soot particles was about $120 \mathrm{~nm}$, and measurement of the particle mass and mobility size gave a mass fractal dimension of $1.90 \pm 0.1$. Using TEM, we found that the primary particles had a mean diameter of $28 \mathrm{~nm}$, with a geometric standard deviation of 1.26. Loading experiments were carried out with the face velocity of $10 \mathrm{~cm} / \mathrm{s}$ on a fiberglass filter media. The pressure drop increased approximately linearly with the loading mass. Filter mass changes were measured after the loading tests, with the accuracy of $0.1 \mathrm{mg}$. The cake thickness was measured using a video-enhanced microscope (VEM, Nikon). With the cake mass $M_{\mathrm{c}}$ and thickness $H$, we can compute the average porosity in the entire cake layer as

$\varepsilon=1-\frac{M_{\mathrm{c}} / \rho}{H A_{\mathrm{f}}}$

where $\rho$ is the particle density, and $A_{\mathrm{f}}$ is the filtration surface area. The average cake porosity $\varepsilon$ in our experiments was 0.95. Endo et al. (1998) developed a model for the pressure drop of the dust cake, with the effect of the particle polydispersity and shape factor considered. They assumed that the particle size distribution followed the log normal distribution, 


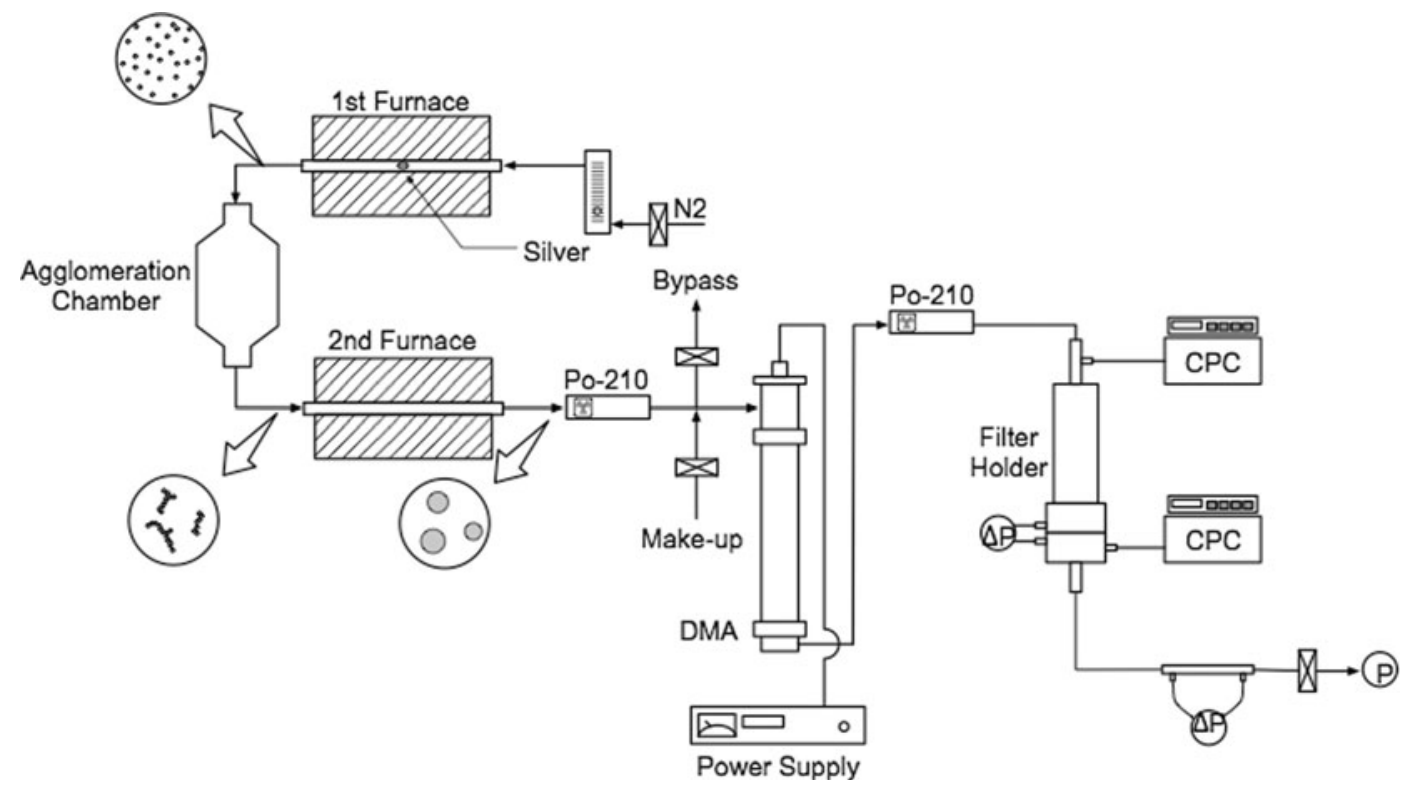

Fig. 12 Schematic of the filtration test system for silver nanoparticle agglomerates

Fig. 13 Results of agglomerate penetration test. The particle morphology changes from open structure to sintered sphere-like particles when the second furnace temperature increases from room temperature to $600{ }^{\circ} \mathrm{C}$

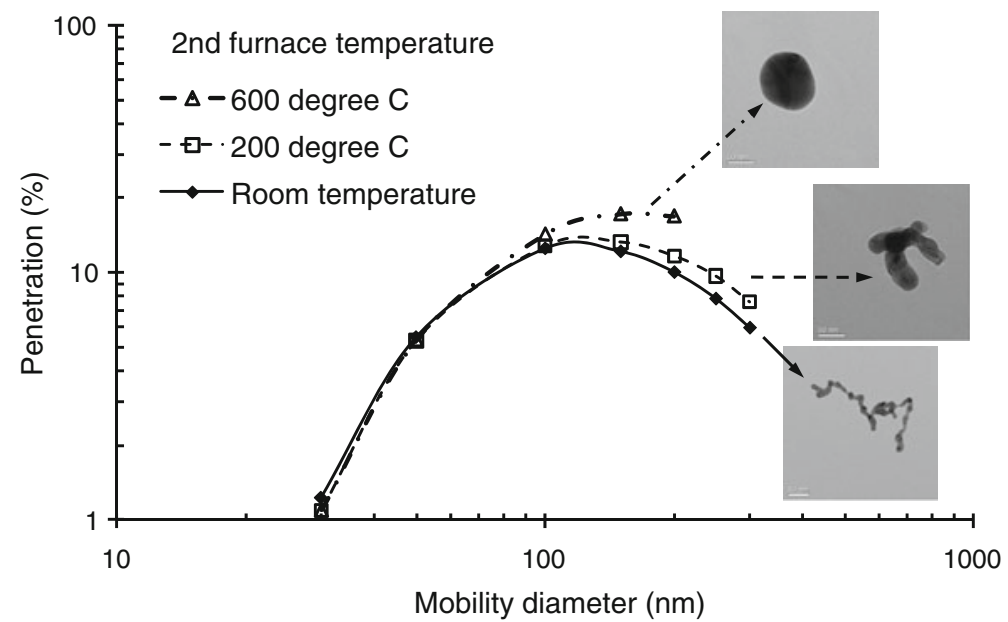

and showed that the pressure drop of the cake layer $\Delta P_{\mathrm{c}}$

$\Delta P_{\mathrm{c}}=18 \mu U_{0} H \frac{(1-\varepsilon) v(\varepsilon) \quad \kappa}{\varepsilon^{2} \quad d_{\mathrm{vg}}^{2} \exp \left(4 \ln ^{2} \sigma_{\mathrm{g}}\right)}$

where $\mu$ is the air viscosity, $U_{0}$ is the face velocity, $v(\varepsilon)$ is the void function, $d_{\mathrm{vg}}$ is the geometric mean of the volume equivalent diameter of the loading particles, $\sigma_{\mathrm{g}}$ is the geometric standard deviation, and $\kappa$ is the dynamic shape factor. The model was developed for compact-structured particles in the micrometer range. We discovered that the model was applicable to agglomerate loading, too. SEM images (e.g., Fig. 14a) showed that individual soot agglomerates were not distinguishable in the dust cake; instead, the cake could be regarded as formed by primary particles. When the size distribution of the primary particles was used in the model of Endo et al., good agreement between the experimental and computed results was obtained (Fig. 14b). 


\section{Conclusions}

Oversight and regulation play a significant role in ensuring responsible and environmentally friendly development of nanotechnology. This, in turn, promotes continuous and sustainable advances of science and industry. Oversight and regulation can inspire and drive EHS studies, and EHS studies provide data and information for development of regulations and guidelines. EHS studies of nanomaterials need input from major research areas, including measurement and characterization; emission, exposure, and toxicity; and control and abatement. Our new instrument, UNPA, demonstrated good capabilities for nanoparticle agglomerate measurement. Exposure measurement at a pilot scale plant showed that nanoparticle release from a manufacturing process can be minimized with proper procedures; however, protection for workers is still needed during special processes, such as cleaning

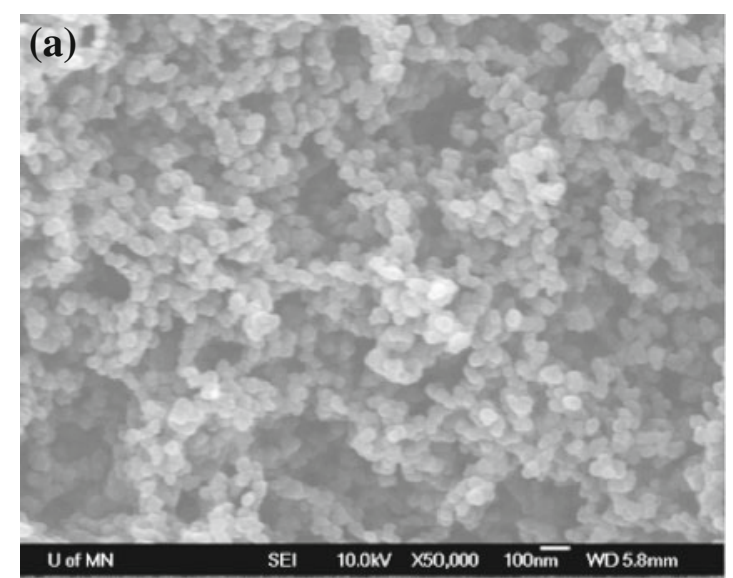

(b)

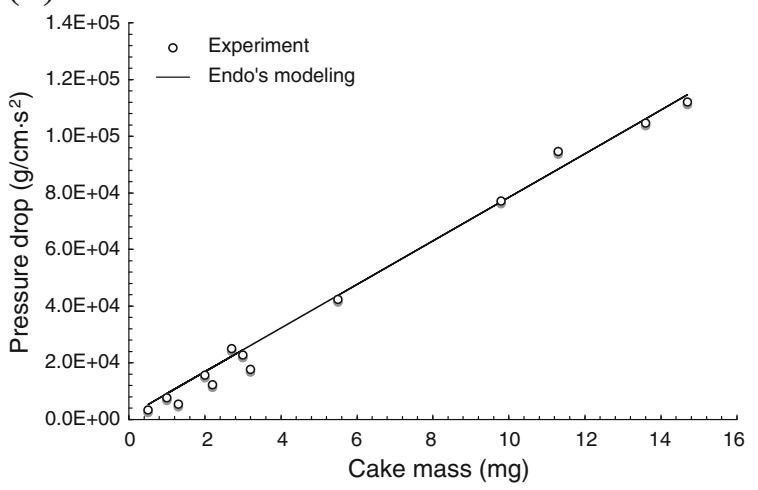

Fig. 14 a An SEM image of the dust cake formed by soot agglomerates. b The pressure drop as a function of the cake mass and packaging. Measurement at a CNT composite production facility showed that CNT agglomerates were released and that there was possible exposure. Animal inhalation experiments were carried out, which demonstrated that our dispersion method can provide airborne CNTs with controlled degree of agglomeration for toxicity studies. Filtration of silver nanoparticles showed that filters were more effective for agglomerates as compared to spheres of the same mobility. Loading studies are important and have bearing on emission regulations. An integrative approach to filtration research is needed to meet modern filtration requirements. EHS research is key to sustainable nanotechnology and will impact environment, energy, transportation, semiconductor, and health care industries.

Acknowledgments Preparation of this article was supported by National Science Foundation (NSF) Grant \#0608791, "NIRT: Evaluating Oversight Models for Active Nanostructures and Nanosystems: Learning from Past Technologies in a Societal Context" (Principal Investigator: S. M. Wolf; Co-PIs: E. Kokkoli, J. Kuzma, J. Paradise, and G. Ramachandran). The research was also partially supported by the National Institute of Environmental Health Sciences (NIEHS) Grant \#1RC2ES018741-01 (sub-grant 100029-D) on "Hazard Assessment and Risk Estimation of Inhaled Nanomaterials Exposure" and by the NSF Grant \#0646236 on "Experimental and Numerical Simulation of the Fate of Airborne Nanoparticles from a Leak in a Manufacturing Process to Assess Worker Exposure." The views expressed are those of the authors and do not necessarily reflect the views of NSF or NIEHS.

\section{References}

Brown RC, Hemingway MA (1995) Electric charge distribution and capacitance of agglomerates of spherical particles: theory and experimental simulation. J Aerosol Sci 26:1197-1206

Cai J, Lu N, Sorensen CM (1993) Comparison of size and morphology of soot aggregates as determined by scattering and electron microscope analysis. Langmuir 9:2861-2867

Chang J-S (1981) Theory of diffusion charging of arbitrarily shaped conductive aerosol particles by unipolar ions. J Aerosol Sci 12:19-26

DeCarlo PF, Slowik JG, Worsnop DR, Davidovits P, Jimenez JL (2004) Particle morphology and density characterization by combined mobility and aerodynamic diameter measurements, part 1: theory. Aerosol Sci Technol 38:1185-1205

Endo Y, Chen D-R, Pui DYH (1998) Effects of particle polydispersity and shape factor during dust cake loading on air filters. Powder Technol 98:241-249 
Fu TH, Cheng MT, Shaw DT (1990) Filtration of chain agglomerate aerosols by model screen filter. Aerosol Sci Technol 13:151-161

Geller M, Biswas S, Sioutas C (2006) Determination of particle effective density in urban environments with a differential mobility analyzer and aerosol particle mass analyzer. Aerosol Sci Technol 40:709-723

Han JH, Lee EJ, Lee JH, So KP, Lee YH, Bae GN, Lee SB, Ji JH, Cho MH, Yu IJ (2008) Monitoring multiwalled carbon nanotube exposure in carbon nanotube research facility. Inhal Toxicol 20:741-749

Hülser TP, Schnurre SM, Wiggers H, Schulz C (2010) Gasphase synthesis of highly-specific nanoparticles on the pilot-plant scale. In: Proceedings of world congress on particle technology (WCPT6)

Johnson TV (2006) Diesel emission control in review, 2006 SAE World Congress, Detroit, MI

Kim SC, Wang J, Emery M, Shin W-G, Mullholand G, Pui DYH (2009a) Structural property effect of nanoparticle agglomerates on particle penetration through fibrous filter. Aerosol Sci Technol 43:344-355

Kim SC, Wang J, Shin W-G, Scheckman J, Pui DYH (2009b) Structural properties and filter loading characteristics of soot agglomerates. Aerosol Sci Technol 43:1033-1041

Kim SC, Chen DR, Qi C, Gelein RM, Finkelstein JN, Elder A, Bentley K, Oberdorster G, Pui DYH (2010) A nanoparticle dispersion method for in vitro and in vivo nanotoxicity study. Nanotoxicology 4:42-51

Koylu UO, Faeth GM, Farias TL, Carvalho MG (1995) Fractal and projected structure properties of soot aggregates. Combust Flame 100:621-633

Kuhlbusch TA, Fissan H (2006) Particle characteristics in the reactor and pelletizing areas of carbon black production. J Occup Environ Hyg 3:558-567

Kuhlbusch TAJ, Neumann S, Fissan H (2004) Number size distribution, mass concentration, and particle composition of PM1, PM2.5 and PM10 in bagging areas of carbon black production. J Occup Environ Hyg 1:660-671

Lall AA, Friedlander SK (2006) On-line measurement of ultrafine aggregate surface area and volume distributions by electrical mobility analysis: I. Theoretical analysis. J Aerosol Sci 37:260-271

Lange R, Fissan H, Schmidt-Ott A (1999) Predicting the collection efficiency of agglomerates in fibrous filter. Part Part Syst Char 16:60-65

Maricq MM, Xu N (2004) The effective density and fractal dimension of soot particles from premixed flames and motor vehicle exhaust. J Aerosol Sci 35:1251-1274

Maynard AD (2006) Nanotechnology: a research strategy for addressing risk. Project on Emerging Nanotechnologies, Washington, DC

Maynard AD, Pui DYH (2007) Nanoparticles and occupational health. Springer, New York

Maynard AD, Baron PA, Foley M, Shvedova AA, Kisin ER, Castranova V (2004) Exposure to carbon nanotube material: aerosol release during the handling of unrefined single-walled carbon nanotube material. J Toxicol Environ Health Part A 67:87-107

McMurry PH, Shepherd M, Vickery JS (2004) Particulate matter science for policy makers: a NARSTO assessment. Cambridge University Press, Cambridge
National Institute for Occupational Safety, Health (NIOSH) (2009) Strategic plan for NIOSH nanotechnology research and guidance-filling the knowledge gaps. Department of Health and Human Services, Washington, DC

Neimark AV, Koylu OU, Rosner DE (1996) Extended characterization of combustion-generated aggregates: selfaffinity and lacunarities. J Colloid Interface Sci 180:590-597

Oberdörster G, Oberdörster E, Oberdörster J (2005) Nanotoxicology: an emerging discipline evolving from studies of ultrafine particles. Environ Health Perspect 113:823-839

Olfert JS, Symonds JPR, Collings N (2007) The effective density and fractal dimension of particles emitted from a light-duty diesel vehicle with a diesel oxidation catalyst. J Aerosol Sci 38:69-82

Park K, Kittelson DB, McMurry PH (2004a) Structural properties of diesel exhaust particles measured by transmission electron microscope (TEM): relationships to particle mass and mobility. Aerosol Sci Technol 38:881-889

Park K, Kittelson DB, Zachariah MR, McMurry PH (2004b) Measurement of inherent material density of nanoparticle agglomerates. J Nanopart Res 6:267-272

Park K, Dutcher D, Emery M, Pagels J, Sakurai H, Scheckman J, Qian S, Stolzenburg MR, Wang X, Yang J, McMurry PH (2008) Tandem measurements of aerosol propertiesa review of mobility techniques with extensions. Aerosol Sci Technol 42:801-816

Poland CA, Duffin R, Kinloch I, Maynard A, Wallace WAH, Seaton A, Stone V, Brown S, MacNee W, Donaldson K (2008) Carbon nanotubes introduced into the abdominal cavity of mice show asbestos-like pathogenicity in a pilot study. Nat Nanotechnol 3:423-428

Pratsinis SE (1998) Flame aerosol synthesis of ceramic powders. Prog Energy Combust Sci 24:197-219

Roco MC (2006) Nanotechnology's future. Sci Am (Magazine)

Rogak SN, Flagan RC, Nguyen HV (1993) The mobility and structure of aerosol agglomerates. Aerosol Sci Technol $18: 25-47$

Ryman-Rasmussen JP, Cesta MF, Brody AR, Shipley-Phillips JK, Everitt JI, Tewksbury EW, Moss OR, Wong BA, Dodd DE, Anderson ME, Bonner JC (2009a) Inhaled carbon nanotubes reach the subpleural tissue in mice. Nat Nanotechnol 4:708-710

Ryman-Rasmussen JP, Tewksbury EW, Moss OR, Cesta MF, Wong BA, Bonner JC (2009b) Inhaled multiwalled carbon nanotubes potentiate airway fibrosis in a murine model of allergic asthma. Am J Resp Cell Mol Biol 40:349-358

Sakamoto Y, Nakae D, Fukumori N, Tayama K, Maekawa A, Imai K, Hirose A, Nishimura T, Ohashi N, Ogata A (2009) Induction of mesothelioma by a single intrascrotal administration of multi-wall carbon nanotube in intact male Fischer 344 rats. J Toxicol Sci 34:65-76

Samson RJ, Mulholland GW, Gentry JW (1987) Structural analysis of soot agglomerates. Langmuir 3:272-281

Shin WG, Wang J, Mertler M, Sachweh B, Fissan H, Pui DYH (2009a) Structural properties of silver nanoparticle agglomerates based on transmission electron microscopy: relationship to particle mobility analysis. J Nanopart Res 11:163-173

Shin WG, Mulholland GW, Kim SC, Wang J, Emery MS, Pui DYH (2009b) Friction coefficient and mass of silver 
agglomerates in the transition regime. J Aerosol Sci 40:573-587

Shin WG, Wang J, Mertler M, Sachweh B, Fissan H, Pui DYH (2010) The effect of particle morphology on unipolar diffusion charging of nanoparticle agglomerates in the transition regime. J Aerosol Sci 41:975-986

Slowik JG, Stainken K, Davidovits P, Williams LR, Jayne JT, Kolb CE, Worsnop DR, Rudich Y, DeCarlo PF, Jimenez JL (2004) Particle morphology and density characterization by combined mobility and aerodynamic diameter measurements. Part 2: application to combustion-generated soot aerosols as a function of fuel equivalence ratio. Aerosol Sci Technol 38:1206-1222

Takagi A, Hirose A, Nishimura T, Fukumori N, Ogata A, Ohashi N, Kitajima S, Kanno J (2008) Induction of mesothelioma in $\mathrm{p} 53 \mathrm{p} /-$ mouse by intraperitoneal application of multi-wall carbon nanotube. J Toxicol Sci 33:105-116
Van Gulijk C, Marijnissen JCM, Makkee M, Moulijn JA, Schmidt-Ott A (2004) Measuring diesel soot with a scanning mobility particle sizer and an electrical lowpressure impactor: performance assessment with a model for fractal-like agglomerates. J Aerosol Sci 35:633-655

Wang J, Chen DR, Pui DYH (2007) Modeling of filtration efficiency of nanoparticles in standard filter media. J Nanopart Res 9:109-115

Wang J, Shin W-G, Mertler M, Sachweh B, Fissan H, Pui DYH (2010) Measurement of nanoparticle agglomerates by combined measurement of electrical mobility and unipolar charging properties. Aerosol Sci Technol 44:97-108

Wentzel M, Gorzawski H, Naumann KH, Saathoff H, Weinbruch S (2003) Transmission electron microscopical and aerosol dynamical characterization of soot aerosols. J Aerosol Sci 34:1347-1370 